This is an author produced version of a paper published in Trends in Ecology \& Evolution.

This paper has been peer-reviewed and is proof-corrected, but does not include the journal pagination.

Citation for the published paper:

Inderjit; Wardle, David; Karban, Richard; Callaway, Ragan M. (2011) The ecosystem and evolutionary contexts of allelopathy. Trends in Ecology \& Evolution. Volume: 26, Number: 12, pp 655-662. http://dx.doi.org/10.1016/j.tree.2011.08.003.

Access to the published version may require journal subscription. Published with permission from: Elsevier.

Standard set statement from the publisher:

Posting and dissemination of authors accepted manuscript is allowed to personal websites, to institutional repositories, or to arXiv.

Epsilon Open Archive http://epsilon.slu.se 


\section{The ecosystem and evolutionary contexts of allelopathy}

5 Inderjit*, David A. Wardle ${ }^{1}$, Richard Karban ${ }^{2}$, and Ragan M. Callaway ${ }^{3}$

6 Department of Environmental Studies, Centre for Environmental Management of Degraded

7 Ecosystems (CEMDE), University of Delhi, Delhi, India; ${ }^{1}$ Department of Forest Ecology and

8 Management, Swedish University of Agricultural Sciences; Umeå, Sweden; ${ }^{2}$ Department of

9 Entomology, University of California Davis, Davis, CA, USA; ${ }^{3}$ Division of Biological Sciences,

10 The University of Montana, Missoula, MT, USA.

11

12 *Corresponding author: Inderjit (inderjitdu@gmail.com)

13

14 Short title: Allelopathy: ecosystem-dependent interactions

15

16

17

18

19

20

21

22

23

24

Type of article: Review

Number of words in the abstract $=97$

Number of words in the manuscript $=3855$

Number of references $=91$

Number of Boxes $=1$

Number of Tables $=1$ 


\section{Abstract}

27 Plants can release chemicals into the environment that suppress the growth and establishment of

28 other plants in their vicinity, a process known as 'allelopathy'. However, chemicals with

29 allelopathic functions have other ecological roles, such as plant defense, nutrient chelation, and

30 regulation of soil biota in ways that affect decomposition and soil fertility. These ecosystem-scale

31 roles of allelopathic chemicals can augment, attenuate or modify their community-scale

32 functions. In this review we explore allelopathy in the context of ecosystem properties, and

33 through its role in exotic invasions consider how evolution might affect the intensity and

34 importance of allelopathic interactions.

36 Key words: allelopathy, allelochemicals, community ecology, evolution, exudates, herbivory,

37 invasion, soil microbes

\section{Allelochemical interactions in the context of communities and ecosystems}

41 How populations are organized into higher units, or “communities”, is a central issue in ecology

42 [1]. The Russian ecologist T.A. Rabotnov [2] hypothesized that adaptation of plant species to the

43 chemistry of other species was crucial to this organization. Rabotnov focused on allelopathic

44 interactions, which involve biochemically based suppression of the establishment and growth of

45 one plant by another. But plant-released secondary chemicals also have powerful effects on

46 decomposition [3], herbivory [4], trophic interactions [5] and nitrogen cycling [6,7] (Figure 1).

47 Allelopathy has been studied a great deal over the last 50 years, but only a few studies have

48 attempted to understand allelochemical interactions among plants in the context of these broader 
49 effects [8-14]. Consideration of allelopathy in this integrated community and ecosystem context

50 requires the recognition of the large number of different processes that can be affected by the

51 same chemical or its derivatives, and the potential for the direct allelochemical effects of plants

52 on each other to be augmented, attenuated, modified or offset [11]. These other interactors can

53 enhance or reduce allelochemical production, change the persistence or effectiveness of

54 allelochemicals in soil, and select for higher or lower allelochemical concentrations over

55 evolutionary time. Understanding allelopathy in the context of communities and ecosystems can

56 be further developed by comparing the potential allelopathic effects of invasive species between

57 their native and introduced ranges [15-18]. Such biogeographic comparisons suggest that

58 evolutionary relationships among plants, and between plants and soil biota, may affect the role of

59 allelopathy in community organization [16].

60 Mere production of chemicals by a plant is not sufficient to ensure their allelopathic potential.

61 Abiotic and biotic environmental conditions determine the allelopathic potential of chemicals in

62 soil [10]. Recent studies have advanced our understanding of allelopathy by examining it in

63 environmental [12,19-21], biogeographic [15,16,22] and evolutionary [23,24] contexts. Our goal

64 is to discuss how (i) biotic and abiotic environmental conditions and (ii) evolutionary history

65 affect the production, fate, and effectiveness of allelopathic compounds in soils (Figure 1).

66 Specifically, we consider how habitat or site-specific characteristics, non-native ecosystems, and

67 environmental variables all influence the release, accumulation, and function of chemicals, and

68 thus affect the organization of natural systems.

69

70 
71 Consumer, competitor and soil microbe effects on allelochemical production and activity

73 The production, storage, and release of allelochemicals are key mechanisms of plant behavior

74 which affect almost all aspects of a plant's ecology [9]. These processes are affected by the

75 abiotic and biotic properties of the ecosystems in which plants grow [25], and chemicals

76 produced by plants in turn have strong effects on ecosystem properties. We propose that by

77 explicitly recognizing and integrating these ecosystem level effects, we will better understand

78 the various allelopathic, defensive, foraging, and signaling roles of chemicals in the organization

79 of natural communities (Figure 1).

80 Under natural conditions, allelopathic effects can result from interactive effects among

81 multiple compounds [26-29]. One of the best understood allelopathic systems involves the root

82 exudates of Sorghum bicolor which can contain up to 85\% sorgoleone [30,31], However, is now

83 recognized that these exudates often contain both sorgoleone and its analogue (the lipid

84 resorcinol) in a 1:1 ratio [31], yielding the opportunity for studying potential interactive effects

85 among these two compounds.

86 Many chemicals released from the roots of plant species function to make nutrients available,

87 often through chelation, and can be quite substrate specific. Some chelators also appear to be

88 allelopathic. Chelating chemicals can degrade either slowly or rapidly, and this can increase or

89 decrease their biological activity $[9,12,14]$. However, many chelators are non-specific and hence

90 will bind with any of the metal ions with affinity decreasing along a lypotropic series. Most

91 natural soils are abundant in metal ions and hence it is difficult to find an uncomplexed chelator

92 under natural conditions. This aspect therefore needs more attention.

93 There is considerable evidence for the direct inhibitory effects of specific allelochemicals

94 isolated from root exudates, leaf leachates and leaf volatiles of plants on other species. However, 
95 in many cases, substantial variation has been found in the field concentrations and production of

96 the chemical, responses of target species, and the chemical's interactions with environmental

97 conditions, other phytochemicals, and other biota [10,12,32]. Such variation in allelochemical-

98 environment interactions makes allelopathy difficult to consistently demonstrate in the field [but

99 see 16,33,34], and has led to conflicting evidence for the ecological relevance of particular

100 chemicals (Box 1) [19,32,35-37]. However, variation in the allelopathic potential of chemicals

101 among environments allows for more realistic appraisals of the role of ecological context in

102 driving allelopathic interactions [12]. Such processes provide alternative hypotheses for the direct

103 effects of allelochemicals on other species, and a broader understanding of the conditional effects

104 of allelopathy. Here we discuss how interactions between chemicals and ecosystem factors affect

105 the production, release, accumulation and activity of allelochemicals (Figure 1).

106

107

Above-ground ecosystem influences on allelopathy

108

109 Biotic components of the ecosystem such as herbivores, competitors, pathogens and belowground

110 decomposers can alter concentrations of chemicals already in plant tissues or released from

111 plants, or stimulate the production of chemicals that are otherwise not present or occur at very

112 low levels $[38,39]$. Here we discuss above-ground biotic influences of ecosystems on allelopathic

113 effects of herbivory-induced volatile chemicals in various environments.

114 Many allelochemicals can be induced by low concentrations of soil nutrients (although the

115 ultimate cue is likely to be low concentrations in tissues). For example, iron deficiencies

116 stimulate highly complex exudation responses [14]. Under iron limitation the roots of Centaurea

117 diffusa prolong the release of 8-hydroxyquinoline that also mobilizes metals and makes them

118 available for plant uptake [14]. Thus, the metal content of soils from different ecosystems is 
119 likely to strongly influence the production and soil availability of 8-hydroxyquinoline, and

120 complex interactions between this allelochemical and metals may also determine its biological

121 activity [14]. Light intensity increases the root exudation of 8-hydroxyquinoline [14], which

122 exhibits a diurnal rhythm and reaches a maximum after 6 hours of exposure to light. Evaluating

123 the role of an allelochemical in the context of its abiotic environment should aid our

124 understanding on its release and allelopathic activities.

125 Induced secondary metabolite-based defenses are common in plants [40], and if the same

126 secondary metabolites or their derivatives are also allelopathic, herbivory might substantially

127 modify allelopathic interactions [see 11]. Karban [8] found that volatiles produced by

128 experimental clipping of sagebrush also inhibited germination and establishment of neighboring

129 plant species, thus providing experimental evidence of an herbivore-enhanced allelopathic effect.

130 The effects of allelochemicals depend not only on environmental conditions but also the genetic

131 landscape. For example, effects of herbivore-induced volatiles on neighboring sagebrush plants

132 were greater when the plants were genetically identical than when genetically different [41].

133 Herbivory induces plant defenses that trigger the release of volatile organic compounds $[38,42]$

134 and accumulation of polyphenolics [43], and some of these chemicals may be allelopathic in

135 nature. Consistent with this, Bi et al. [44] found that exogenous application of methyl jasmonate,

136 a chemical that induces herbivore defenses in many plant species, led to the accumulation of

137 phenolics in rice and increased its allelopathic effects on other plants. 
142 Below-ground influences of ecosystem processes driven by soil biota, genetic effects on root

143 interactions, and complex interactions among different root exudates appear to shape allelopathic

144 interactions. The general importance of soil communities in influencing the qualitative and

145 quantitative availability of allelochemicals is well established [45,46]. Microbial transformation

146 of biologically active chemicals commonly degrades their function, and evaluation of the activity

147 of an allelochemical in microbe-free substratum may therefore not be ecologically relevant. For

148 example, allelopathic effects of m-tyrosine, a metabolite exuded by the roots of Festuca rubra

149 ssp. commutata, have been demonstrated through filter paper bioassays free from naturally

150 occurring microbes [47]. However, Kaur et al. [19] showed that allelopathic effects of m-

151 tyrosine were only evident in sterilized soil and diminished sharply in non-sterile soil with an

152 intact microbial community. Even this type of comparison must be interpreted with caution

153 because the scale of ecological interactions among roots, microbes and allelochemicals is

154 microscopic and ephemeral. For example, Bertin et al. [48] found that the predicted half-life of

155 m-tyrosine in soil in laboratory conditions was less than 1 day, indicative of rapid microbial

156 degradation. Sorgoleone, a major component of root exudates of Sorghum bicolor, is a potent

157 allelochemical [30] and microorganisms present in North American soils readily use it as a

158 carbon source [49]. It has been shown that the methoxy group of sorgoleone, which is responsible

159 for much of its activity, degrades rapidly in soil [49].

160 In addition to the direct effects of allelochemicals on plant growth, their indirect effects may

161 be mediated by microbial activity. Meier and Bowman [50] compared the effects of several

162 allelochemical fractions from a phenolic-rich alpine forb, Acomastylis rossii, on soil respiration

163 and the growth of the grass Deschampsia caespitosa. They found that some fractions had a direct 
164 phytotoxic effect (i.e., which did not increase soil respiration but killed $D$. caespitosa) while

165 others appeared to work indirectly through the soil microbial community (i.e., which stimulated

166 soil respiration and reduced plant growth and plant $\mathrm{N}$ concentration). Their results provide a

167 compelling example of how phenolic compounds can inhibit root growth directly as well as

168 through interacting with soil biota. In another example, Alliaria petiolata can have negative

169 impacts on arbuscular mycorrhizal (AM) fungi and regeneration of seedlings native to North

170 America in soil from North America [51], but much weaker effects on AM fungi in soils from

171 Europe where it is native. Cantor et al. [52] showed that even very low field concentrations of

172 allyl isothiocynate (ca. $0.001 \mathrm{mM})$ produced in the presence of $A$. petiolata strongly inhibited the

173 spore germination of the AM fungus Glomus clarum. However, Barto et al. [53] did not find

174 effects of $A$. petiolata extracts on the AM fungal colonization of roots or soils, and suggested that

175 potential alleopathic effects of $A$. petiolata might be due to direct inhibition of plant seedlings

176 and fungus before the formation of symbiosis.

177 The impacts of seasonal variation on the production and accumulation of allelochemicals [54]

178 and soil microbial communities [55] also contribute to the context-specificity of allelopathic

179 effects. For example, Alliaria petiolata accumulates glucotropaeolin three times more rapidly in

180 autumn than in spring, while accumulation of alliarinoside is highest in spring [54]. Fungal

181 communities and ectomycorrhizal colonization rates showed linear and curvilinear responses to

182 alliarinoside and glucosinolate concentrations, respectively [24]. Increasing concentrations of

183 alliarinoside were found to alter AM fungal communities, leading to a decline in AMF

184 colonization of Quercus rubra roots [24].

185 Belowground interactions among plants may also be genotype or ecotype dependent. For

186 example, when the roots of different Ambrosia dumosa plants make contact they often stop

187 growing, but there is a geographic and genotypic aspect to this response. For example, roots of 
188 the plants from the same region show strong contact inhibition, but roots from plants from

189 different regions do not [56,57]. Cakile edentula plants allocate biomass differently to roots if

190 they are grown in the same pots shared by genetic relatives (kin) compared to pots shared by

191 strangers [58]. Lankau [59] reported that investment in high tissue concentrations of sinigrin

192 produced by Brassica nigra gave it an advantage in interspecific competition but a disadvantage

193 in intraspecific competition. Further, selection for B. nigra individuals that produced high levels

194 of sinigrin was stronger when grown with other species than with other individuals of its own 195 species.

196 Coexisting plant species can differ greatly in their growth response to allelochemicals 197 produced by a given plant species, and allelopathic effects can be highly species-specific

$198 \quad[16,22,60]$. As such, there is a wide range of abilities (and perhaps mechanisms) among species

199 to protect themselves from chemical effects of their neighbors. Weir et al. [61] found that

200 Gaillardia grandiflora and Lupinus sericeus secrete oxalate in response to catechin exposure,

201 which could make these two species resistant to C. stoebe invasion. Exogenous application of

202 oxalate blocks the production of reactive oxygen species in the target plants, minimizing

203 oxidative damage caused by catechin. Such variation in the species-specific response of target

204 species may play a crucial role in the organization or assembly of plant communities in a similar

205 manner that it does for microbial communities [62], and provides an opportunity for allelopathy

206 to drive natural selection [63]. Variation in the ecological roles of secondary compounds is better

207 understood for consumer defense than for allelopathy, but for both types of interactions variation

208 is an important aspect of the effects of chemicals on communities and populations.

209 Issues of spatial scale and patchiness make studies of the roles of allelochemicals in soils

210 difficult to interpret. The effects of allelochemicals in soils are generally examined using "bulk

211 soils”, where allelochemicals are added to a volume of soil that is orders of magnitude greater 
212 than the soil volume in which the interactions occur. 'Realistic' concentrations of

213 allelochemicals are estimated for the average of the large soil volume. However, the action of

214 root-exuded chemicals often takes place at root-root interfaces. The use of estimated soil

215 concentrations is just one way to explore allelopathy in a reasonably realistic manner, but they

216 have limitations for the determination of the allelopathic functions of chemicals. If an

217 allelochemical is experimentally applied to soil in such a way as to allow it to transform before

218 contact with roots [12,19,34,37], then the failure to find an effect cannot be taken as evidence that

219 effects do not occur when roots are in close proximity to each other. This issue is, however, less

220 relevant when allelochemicals enter the soil through release from foliage or decomposition of

221 plant litter.

222

223 Biogeographic comparisons of allelopathy: evolutionary changes in allelochemical effects

225 The effects of allelopathy are also dependent on the evolutionary history of the interaction.

226 Understanding the mechanisms by which many exotic invasive plants strongly suppress their

227 neighbors in invaded but not native ranges has attracted growing recent attention. Allelopathy

228 and other biochemically driven interactions may contribute to the success of some exotic invasive

229 plants, and when either specific allelochemicals or general allelopathic effects are stronger

230 against potentially evolutionarily naïve species in invaded ranges, we gain insight into how

231 evolutionary history affects biological organization [64]. Biogeographical comparisons of the

232 ecological and biochemical traits of species in introduced and native ranges have proven useful

233 for evaluating mechanisms of invasion [65]. Examining the production and/or accumulation of

234 allelochemicals in novel and native environments, and the sensitivity of native residents and soil

235 communities to novel chemicals, can help understand these mechanisms. 
236 The Novel Weapons Hypothesis (NWH) provides a possible explanation for biogeographic

237 patterns of interactions in different ecosystems. The NWH was first proposed in the context of

238 allelopathy as a potential mechanism for the success of Centaurea diffusa as an invader in North

239 America [66], and subsequently as a component of invasion by C. stoebe [67]. Recent studies on

240 biogeographic comparisons of exotic species in native and introduced ranges have shown some

241 support for NWH [15,16,18,68,69]. A recent meta-analysis of hypotheses for invasions, focusing

242 on trees, found that published evidence for the NWH resulted in a stronger effect size in support

243 of the idea than the effects sizes of six other hypotheses [70]. Barto et al. [71] provided evidence

244 in support of NWH by showing that the allelochemical profile of invasive A. petiolata was not

245 shared by any native Brassicaceae in North America. Further, Callaway and Ridenour [67]

246 suggested that stronger allelopathic effects in invaded regions could lead to selection for greater

247 allelopathic production and thus increased competitive ability.

248 Biogeographic differences in the effects of particular compounds between native and invaded

249 ranges may occur in part through a lack of adaptation by species and soil communities in the

250 invaded ranges. However, these types of biogeographic differences may also emerge or intensify

251 because of particular conditions in the novel environment. As such, soil biota can be powerful

252 ecosystem mediators of biogeographic differences in allelopathic effects [46]. For example, soil

253 microbial taxa that metabolize specific chemicals are likely to have undergone evolution to do so,

254 or at least to utilize a related group of chemicals. If plants that occur in a given region do not

255 produce a particular allelochemical, then those soil microbes that are required to metabolize it

256 may not be present when it is introduced by an invader. Thus, novel chemicals produced by

257 invaders may have prolonged resident times in invaded ranges and therefore be more biologically

258 active. Such indirect processes may reinforce biogeographic differences in plant-soil feedbacks

259 involving invasive species [72]. 
260 Soil communities from non-native ranges have also been shown to eliminate allelopathic

261 effects of exotic plants. For example, the invader A. petiolata exerts allelopathic effects through

262 glucosinolate exudation on the native species Platanus occidentalis in sterilized soil but not in

263 non-sterile soil from the invaded range [73]. Future research would be required to determine

264 whether soil microbial communities from locations that differ in their invasion history of $A$.

265 petiolata also differ in their ability to degrade glucosinolate.

266

267 Potential evolutionary relationships: temporal declines in allelochemicals from invasive

268 species

269

270 Plant species that are introduced into a novel environment would likely evolve in response to new

271 conditions over time, and other species that are native to that environment may in turn evolve in

272 response to the introduced species [16]. Such evolutionary responses have been reported for

273 populations of Trifolium repens that have co-adapted to (and with) local competitors [74], and for

274 populations of native soapberry bugs (Leptocoris tegalicus) that have adapted to various

275 introduced host plants [75]. Some native residents in the naturalized range of C. stoebe have

276 exhibited tolerance to it relative to individuals of other native species that have not previously

277 encountered the invader [76]. Individuals grown from seeds of parents that have survived

278 exposure to allelochemicals from C. stoebe have become more resistant to its invasion. This is

279 consistent with the NWH, and suggests that allelopathy may play a role in evolution between

280 neighbors in the non-native ranges.

281 Biogeographic variation in the production of volatile sesquiterpenes in particular could be due

282 to differences in herbivore densities between the native and introduced ranges [77]. Recently, it

283 has been shown [15] that lower amounts of volatile chemicals were released by plants from 
284 exotic populations of the invasive plant Ageratina adenophora than by plants from native

285 populations grown in a common environment. However, it is not known whether such differences

286 in volatile emissions are evolutionary consequences of interactions with other species or due to

287 founder effects.

288 An allelochemical produced by a species can provide multiple ecological functions, making its

289 effects highly dependent on specific environmental conditions. Further, allelochemicals with

290 multiple functions should be selected for because this spares the plant the cost of producing

291 several different compounds [11]. Glucosinolates and their derivatives have been found to have

292 multiple functions as mediators of plant-plant, plant-microbe, and plant-insect interactions [59].

293 Lankau and Kliebenstein [78] found that competition and herbivory determined the accumulation

294 and fitness consequences of sinigrin for B. nigra. Further, it has been shown that the fitness costs

295 and benefits of sinigrin conformed to optimal defense theory only in the absence of competition,

296 apparently due to its multiple functions [11,78]. Further, Oduor et al. [79] found that invasive

297 populations of $B$. nigra had higher levels of sinigrin which defends the invader against generalist

298 herbivores. An increase in resistance against generalist herbivores and growth performance of $B$.

299 nigra in its introduced ranges compared to its native range further supports the hypothesis that

300 defenses have shifted [79]. Sinigrin from B. nigra is also reported to possess allelopathic

301 activities, which provide a competitive advantage to B. nigra over heterospecific neighbors [59].

302 Lankau et al. [23,24] examined the production, release and impact of glucosinolates from $A$.

303 petiolata along a gradient of invasion history i.e., from early invaded to recently-invaded

304 populations. They found a significant decline in the production of glucosinolates and an increase

305 in the community's resistance to A. petiolata invasion over time. Following an initial decline in

306 the number of operational taxonomic units (OTUs) of bacteria, fungi and AM fungi, an increase

307 was observed in older invaded sites [24]. The observed development of resistance to exotic 
308 invasion in late invasion stages could lead to more species rich native communities. However, the

309 eventual outcome of the evolutionary changes is still unclear. Lankau et al. [80] found that the

310 higher production of sinigrin by introduced B. nigra suppressed mycorrhizal abundance, which

311 adversely affected the growth of heterospecific competitors but not non-mycorrhizal conspecifics.

312 Such rapid selection based on tradeoffs between competitive advantages against either

313 conspecifics or heterospecifics contributes to intransitive competitive networks which affect

314 genetic and species diversity in communities [80]. Studying evolutionary relationships between

315 native and non-native communities and ecosystems along gradients of invasion history has

316 significant potential for improving understanding of the role of allelopathy in community

317 organization.

318

319 Conclusions

320

321 It is important to identify how variation in the environment establishes conditionality in

322 allelopathic interactions. Sources of such variation include (1) the impact of soil chemistry on

323 production and effects of allelochemicals, (2) the impact of consumers, competitors, and soil

324 microbes on production and effects of allelochemicals, (3) evolutionary changes in

325 allelochemical effects, and (4) declines in allelochemical production and activity from invasive

326 species over time. A major gap in current allelopathy research involves the role of conditional

327 ecosystem factors that drive allelopathic processes and how these change over space and time

328 (Figure 1). Further, despite recent advances, we still have a limited understanding of the role of

329 evolution over time in the production, release and eventual loss of activity of biogeographically

330 novel chemicals. 
331 The production, fate, and effectiveness of allelopathic compounds in soils is influenced by

332 environmental conditions and evolutionary history, generating a need for allelopathic interactions

333 to be studied across spatial and temporal scales (Figure 1). Over very small scales (microns to

334 millimeters; seconds to hours), processes in the rhizosphere, such as microbial-driven breakdown

335 of allelochemicals or metal chelation, dominate the influences of allelochemicals. Over small

336 scales (millimeters to meters; hours to months), organismal responses are important, for instance,

337 the increased production of chemicals following herbivore attack. At the medium scale (meters to

338 kilometers; months to years), variation in the plant and soil communities, and abiotic soil

339 conditions become increasingly important, if different species are more or less susceptible to the

340 allelochemicals. Finally, at the large scales (kilometers and beyond; years and beyond), the

341 evolutionary history of the allelopathic plant and the recipient soil and plant community assumes

342 increasing significance (Figure 1).

343 Continuing to quantify various aspects of how ecosystem factors influence allelopathy is key

344 to better understanding of how plants interact with each other. Other important steps would

345 include greater focus on conducting experiments under natural conditions, comparing single

346 chemical effects to whole-exudate effects, profiling metabolites, and conducting bioassays in

347 search of unidentified compounds that mediate these interactions. More generally, there is a

348 greater need for understanding of how biotic and abiotic environmental conditions and

349 evolutionary history affect the production, fate, and effectiveness of allelopathic compounds in

350 soils. Recent work linking chemical ecology to biogeography and evolutionary biology has

351 provided new perspectives on biochemical processes in ecosystems. Expanded use of

352 biogeographical and evolutionary approaches will improve our understanding of the release of

353 allelochemicals over a range of abiotic and biotic conditions and how those conditions determine 354 the outcomes of allelochemical interactions. 


\section{Acknowledgements}

357

358 Inderjit acknowledges research funding from the University of Delhi and Council of Scientific \&

359 Industrial Research (CSIR). Ragan M. Callaway thanks the National Science Foundation and

360 DoD SERDP for support, and David A. Wardle acknowledges support from a Wallenberg

361 Scholars award. We thank two reviewers for their valuable comments. 


\section{References}

1. Lortie, C.J. et al. (2004) Rethinking plant community theory. Oikos 107, 433-438

2. Rabotnov, T.A. (1982) Importance of the evolutionary approach to the study of allelopathy. Ékologia 3, 5-8

3. Hättenschwiler, S., Coq, S., Barantal, S. and Handa, I.T. (2010) Leaf traits and decomposition in tropical rainforests: revisiting some commonly held views and towards a new hypothesis. New Phytol. 189, 950-965

4. Karban, R., Shiojiri, K., Huntzinger, M. and McCall, A.C. (2006) Damage-induced resistance in sagebrush: volatiles are key to intra- and interplant communication. Ecology 87, 922-930

5. Hättenschwiler, S. and Jørgensen, H.B. (2010) Carbon quality rather than stoichiometry controls litter decomposition in a tropical rain forest. J. Ecol. 98, 754-763

6. Northup, R.R., Dahlgren, R.A. and McColl, J.G. (1998) Polyphenols as regulators of plantlitter-soil interactions in northern California’s pygmy forest: a positive feedback?

Biogeochemistry 42, 189-220

7. Hättenschwiler, S. and Vitousek, P. (2000) The role of polyphenols in terrestrial ecosystem nutrient cycling. Trends Ecol. Evol. 15, 238-243

8. Karban, R. (2007) Experimental clipping of sagebrush inhibits seed germination of neighbours. Ecol. Lett. 10, 791-797

9. Metlen, K.L., Aschehoug, E.T. and Callaway, R.M. (2009) Plant behavioural ecology: dynamic plasticity in secondary metabolites. Plant Cell Environ. 32, 641-653

10. Inderjit and Weiner, J. (2001) Plant allelochemical interference or soil chemical ecology? Persp. Plant Ecol. Evol. Systemat. 4, 3-12

11. Siemens, D., Garner, S., Mitchell-Olds, T. and Callaway, R.M. (2002) The cost of defense in the context of competition. Brassica rapa may grow and defend. Ecology 83, 505-517

12. Pollock, J.L., Callaway, R.M., Thelen, G.C. and Holben, W.E. (2009) Catechin-metal interactions as a mechanism for conditional allelopathy by the invasive plant, Centaurea maculosa. J. Ecol. 97, 1234-1242

13. Lankau, R.A. and Strauss, S.Y. (2008) Community complexity drives patterns of natural selection on a chemical defense of Brassica nigra. Am. Nat. 171, 150-161

14. Tharayil, N., Bhowmik, P.C., Alpert, P., Walker, E., Amarasiriwardena, D. and Xing, B. (2009) Dual purpose secondary compounds: phytotoxin of Centaurea diffusa also facilitates nutrient uptake. New Phytol. 181, 424-434

15. Inderjit et al. (2011) Volatile chemicals from leaf litter are associated with invasiveness of a neotropical weed in Asia. Ecology 92, 316-324

16. Thorpe, A.S., Thelen, G.C., Diaconu, A. and Callaway, R.M. (2009) Root exudate is allelopathic in invaded community but not in native community: field evidence for the novel weapons hypothesis. J. Ecol. 97, 641-645

17. Ens, E.J., French, K. and Bremner, J.B. (2009) Evidence for allelopathy as a mechanism of community composition change by an invasive exotic shrub, Chrysanthemoides monifera ssp. rotundata. Plant Soil 316, 125-137

18. Zhang, D., Zhang, J., Yang, W. and Wu, F. (2010) Potential allelopathic effect of Eucalyptus grandis across a range of plantation ages. Ecol. Res. 25, 13-23

19. Kaur, H., Kaur, R., Kaur, S., Baldwin, I.T. and Inderjit (2009) Taking ecological function seriously: soil microbial communities can obviate allelopathic effects of released metabolites. PLOS ONE, 4, e4700 
410

411

412

413

414

415

416

417

418

419

420

421

422

423

424

425

426

427

428

429

430

431

432

433

434

435

436

437

438

439

440

441

442

443

444

445

446

447

448

449

450

451

452

453

454

455

456
20. Tharayil, N., Bhowmik, P.C. and Xing, B. (2006) Preferential sorption of phenolic phytotoxins to soil: implications for the availability of allelochemicals. J. Agric. Food Chem. 54, 3033-3040

21. Tharayil, N., Bhowmik, P.C. and Xing, B. (2008) Phyto-availability of allelochemicals as affected by companion compounds in soil-microbial systems. J. Agric. Food Chem.. 56, $3706-3713$

22. He, W.M. et al. (2009) Novel weapons and invasions: biogeographic differences in the competitive effects of Centaurea maculosa and its root exudates ( \pm )-catechin. Oecologia 159, 803-815

23. Lankau, R.A., Nuzzo, V., Spyreas, G. and Davis A.S. (2009) Evolutionary limits ameliorate the negative impact of an invasive plant. Proc. Natl. Acad. Sci. USA 106, 15362-15367

24. Lankau, R.A. (2011) Resistance and recovery of soil microbial communities in the face of Alliaria petiolata invasions. New Phytol. 189, 536-548

25. Wardle, D.A., Nilsson, M.C., Gallet, C. and Zackrisson, O. (1998) An ecosystem level perspective of allelopathy. Biol. Rev. 73, 305-319

26. Blum, U., Dalton, B.R. and Shann, J.R. (1985) Effects of various mixtures of ferulic acid and some of its microbial metabolic products on cucumber leaf expansion and dry matter in nutrient culture. J. Chem. Ecol. 11, 619-641 2

27. Blum, U., Gerig, T. M. and Weed, S.B. (1989) Effects of mixtures of phenolic acids on leaf area expansion of cucumber seedlings grown in different $\mathrm{pH}$ Portsmouth A1 soil materials. J. Chem. Ecol. 15, 2413-2423

28. Gerig, T. M. and Blum, U. (1993) Modification of an inhibition curve to account for effects of a second compound. J. Chem. Ecol. 19, 2783-2790

29. Inderjit, Striebig, J. and Olofsdotter, M. (2002) Joint action of phenolic acid mixtures and its significance in allelopathy research. Physiol. Plant. 114: 422-428 6

30. Baerson, S.R. et al. (2008) A functional genomics investigation of allelochemical biosynthesis in Sorghum bicolor root hairs. J. Biol. Chem. 283, 3231-3247

31. Dayan, F.E., Howell, J. and Weidenhamer, J.D. (2009) Dynamic root exudation of sorgoleone and its in planta mechanism of action. J. Exp. Bot. 60, 2107-2117

32. Inderjit, Callaway, R.M. and Vivanco, J.M. (2006) Plant biochemistry helps to understand invasion ecology. Trends Plant Sci. 11, 574-580

33. Nilsson, M-C. (1994) Separation of allelopathy and resource competition by the boreal dwarf shrub Empetrum hermaphroditum Hagerup. Oecologia 98, 1-7

34. Inderjit, Pollock, J.L., Callaway, R.M. and Holben, W. (2008) Phytotoxic effects of ( \pm )catechin in vitro, in soil, and in the field. PLoS One 3, e2536.

35. Blair, A.C., Nissen, S.J., Brunk, G.R. and Hufbauer, R.A. (2006) A lack of evidence for an ecological role of the putative allelochemical (+/-)-catechin in spotted knapweed invasion success. J. Chem. Ecol. 32, 2327-2331

36. Chobot, V., Huber, C., Trettenhahn, G. and Hadacek, F. (2009) ( \pm )-catechin: chemical weapon, antioxidant, or stress regulator? J. Chem. Ecol. 35, 980-996

37. Duke, S.O. et al. (2009) Is (-)-catechin a novel weapon of spotted knapweed (Centaurea stoebe)? J. Chem. Ecol. 35, 141-153

38. Baldwin, I.T., Halitschke, R., Paschold, A., von Dahl, C.C. and Preston, C.A. (2006) Volatile signaling in plant-plant interactions: "Talking trees" in the genomics era. Science 311, 812-815

39. Lohmann, M., Scheu, S. and Müller, C. (2009) Decomposers and root feeders interactively affect plant defence in Sinapis alba. Oecologia 160, 289-298 
457

458

459

460

461

462

463

464

465

466

467

468

469

470

471

472

473

474

475

476

477

478

479

480

481

482

483

484

485

486

487

488

489

490

491

492

493

494

495

496

497

498

499

500

501

40. Agrawal, A.A. (1998) Induced responses to herbivory and increased plant performance. Science 279, 1201-1202.

41. Karban, R. and Shiojiri, K. (2009) Self-recognition affect plant communication and defense. Ecol. Lett. 12, 502-506

42. Karban, R. (2010) The ecology and evolution of induced resistance against herbivores. Func. Ecol. 25, 339-347

43. Roitto, M. et al. (2008) Induced accumulation of phenolics and sawfly performance in Scots pine in response to previous defoliation. Tree Physiol. 29, 207-216

44. Bi, H.H., Zheng, R.S., Su, L.M., An, M. and Luo, S.M. (2007) Rice allelopathy induced by methyl jasmonate and methyl salicylate. J. Chem. Ecol. 33, 1089-1103

45. Inderjit. (2005) Soil microorganisms: an important determinant of allelopathic activity. Plant Soil 274, 227-236

46. Inderjit and van der Putten, W.H. (2010) Impacts of soil microbial communities on exotic plant invasion. Trends Ecol. Evol. 25, 512-519

47. Bertin, C. et al. (2007) Grass roots chemistry: meta-tyrosine, an herbicidal nonprotein amino acid. Proc. Natl. Acad. Sci. USA 104, 16964-16969

48. Bertin, C., Harmon, R., Akaogi, M., Weidenhamer, J.D. and Weston, L.A. (2009) Assessment of the phytotoxic potential of m-tyrosine in laboratory soil bioassays. J. Chem. Ecol. 35, 1288-1294

49. Gimsing, A.L., Bælum, J., Dayan, F.E., Locke, M.E., Sejerø, L.H. and Jacobsen, C.S. (2009) Mineralization of the allelochemical sorgoleone in soil. Chemosphere 76, 10411047

50. Meier, C.L. and Bowman, W.D. (2008) Phenolic-rich leaf carbon fractions differentially influence microbial respiration and plant growth. Oecologia 158, 95-107

51. Callaway, R.M. et al. (2008) Novel weapons: invasive plant suppresses fungal mutualists in America but not in its native Europe. Ecology 89, 1043-1055

52. Cantor, A., Hale, A., Aaron, J., Trow, M.B. and Kalisz, S. (2011) How allelochemical concentrations detected in garlic mustard-invaded forest soil inhibit fungal growth and AMF spore germination. Biol. Invs. (in press)

53. Barto, K., Friese, C. and Cipollini, D. (2010) Arbuscular mycorrhizal fungi protect a native plant from allelopathic effects of an invader. J. Chem. Ecol. 36, 351-360

54. Barto, E.K. and Cipollini, D. (2009) Half-lives and field soil concentrations of Alliaria petiolata secondary metabolites. Chemosphere 76, 71-75

55. Lankau, R.A. (2011) Intraspecific variation in allelochemistry determines an invasive species’ impact on soil microbial communities. Oecologia 165, 453-463

56. Mahall, B.E. and R.M. Callaway. (1996) Geographic and genetic contributions to root communication in Ambrosia dumosa. Amer. J. Bot. 83, 93-98

57. Mahall, B.E. and R.M. Callaway. (1991) Root communication among desert shrubs. Proc. Natl. Acad. Sci. USA 88, 874-876

58. Dudley, S.A. and File, A.L. (2007) Kin recognition in an annual plant. Biol. Lett. 3, 435438

59. Lankau, R. (2008) A chemical trait creates a genetic trade-off between intra- and interspecific competitive ability. Ecology 89, 1181-1187.

60. Gómez-Aparicio, L. and Canham, C.D. (2008) Neighbourhood analysis of the allelopathic effects of the invasive tree Ailanthus altissima in temperate forests. J. Ecol. 96, 447-458 
502

503

504

505

506

507

508

509

510

511

512

513

514

515

516

517

518

519

520

521

522

523

524

525

526

527

528

529

530

531

532

533

534

535

536

537

538

539

540

541

542

543

544

545

546

547

548

61. Weir, T.L. et al. (2006) Oxalate contributes to the resistance of Gaillardia grandiflora and Lupinus sericeus to a phytotoxin produced by Centaurea maculosa. Planta 223, 785-795

62. Callaway, R.M. and Howard, T.G. (2006) Competitive networks, indirect interactions, and allelopathy: a microbial viewpoint on plant communities. Prog. Bot. 68, 317-335

63. Callaway, R.M., Hierro, J.L. and Thorpe, A.S. (2005) Evolutionary trajectories in plant and soil microbial communities: Centaurea invasions and the geographic mosaic of coevolution. In Exotic Species Invasions: Insights into Ecology, Evolution and Biogeography (Sax, D.F., Gaines, S.D. and Stachowicz, J.J., eds.), pp. 341-363. Sinauer, Sunderland

64. Inderjit and Callaway, R.M. (2003) Experimental designs for the study of allelopathy. Plant Soil 256, 1-11

65. Hierro, J.L., Maron, J.L. and Callaway, R.M. (2005) A biogeographical approach to plant invasions: the importance of studying exotics in their introduced and native range. J. Ecol. 93, 5-15

66. Callaway, R.M. and Aschehoug, E.T. (2000) Invasive plant versus their new and old neighbors: a mechanism for exotic invasion. Science 290, 521-523

67. Callaway, R.M. and Ridenour W.M. (2004) Novel weapons: invasive success and the evolution of increased competitive ability. Front. Ecol. Environ. 2, 436-443

68. Kim, Y.O. and Lee, E.J. (2011) Comparison of phenolic compounds and the effects of invasive and native species in East Asia: support forb the novel weapons hypothesis. Ecol. Res. 26, 87-94

69. Ni, G.Y., Schaffner, U., Peng, S.L. and Callaway, R.M. (2011) Acroptilon repens, an Asian invader, has stronger competitive effects on species from America than species from its native range. Biol. Invas. 12, 3653-3663

70. Lamarque, L.J., Delzon, S. and Lortie, C.J. (2011) Tree invasions: a comparative test for the dominant hypotheses and functional traits. Biol. Invas. (in press)

71. Barto, K., Powell, J.R. and Cipollini, D. (2010) How novel are the chemical weapons of garlic mustard in North America forest understories. Biol. Invas. 12, 3465-3471

72. Callaway, R.M., Thelen, G.C., Rodriguez, A. and Holben, W.E. (2004) Soil biota and exotic plant invasion. Nature 427, 731-733

73. Lankau, R.A. (2010) Soil microbial communities alter allelopathic competition between Alliaria petiolata and a native species. Biol. Invas. 12, 2059-2068

74. Turkington, R. (1989) The growth, distribution and neighbor relationships of Trifolium repens in a permanent pasture. V. The coevolution of competitors. J. Ecol. 77, 717-733

75. Carroll, S.P. et al. (2005) And the beak shall inherit - evolution in response to invasion. Ecol. Lett. 8, 944-951

76. Callaway, R.M., Ridenour, W.M., Laboski, T., Weir, T. and Vivanco, J.M. (2005) Natural selection for resistance to the allelopathic effects of invasive plants. J. Ecol. 93, 576-583

77. Mooney, K.A., Halitschke, R., Kessler, A. and Agrawal, A.A. (2010) Evolutionary tradeoff in plants mediate the strength of trophic cascades. Science 327, 1642-1644

78. Lankau, R.A. and Klienbenstein, D.J. (2009) Competition, herbivory and genetics interact to determine the accumulation and fitness consequences of a defense metabolite. J. Ecol. 97, 78-88

79. Oduor, A.M.O., Lankau, R.A., Strauss, S.Y. and Gómez, J.M. (2011) Introduced Brassica nigra populations exhibit greater growth and herbivore resistance but less tolerance than native populations in the native range. New Phytol. 191, 536-544 
549

550

551

552

553

554

555

556

557

558

559

560

561

562

563

564

565

566

567

568

569

570

571

572

573

574

575

576

577

578
80. Lankau, R.A., Wheeler E., Bennett, A.E. and Strauss, S.Y. (2011) Plant-soil feedbacks contribute to an intransitive competitive network that promotes both genetic and species diversity. J. Ecol. 99, 176-185

81. Calow, P. (1999) Blackwell's Concise Encyclopedia of Ecology. Blackwell, Oxford

82. Stermitz, F.R., Hufbauer, R.A and Vivanco, J.M. (2009) Retraction. Plant Physiol. 151, 967

83. Perry, L.G., Thelen, G.C., Ridenour, W.M., Callaway, R.M., Paschke, M.W. and Vivanco, J.V. (2007) Concentrations of the allelochemical (+/-)-catechin in Centaurea maculosa soils. J. Chem. Ecol. 33, 2337-2344

84. Schultz, M.J. (2008) Soil ecological interactions of spotted knapweed and native plant species. M.S. Thesis, Colorado State University, Fort Collins, Colorado

85. Tharayil, N. and Triebwasser, D.J. (2010) Elucidation of a diurnal pattern of catechin exudation by Centaurea stoebe. J. Chem. Ecol. 36, 200-204

86. Marler, M.J., Zabinski, C.A., Wojtowicz, T. and Callaway, R.M. (1999) Mycorrhizae and fine root dynamics of Centaurea maculosa and native bunchgrasses in western Montana. Northwest Sci. 73, 217-224

87. LeJeune, K.D. and Seastedt, T.R. (2001) Centaurea species: the forb that won the west. Conser. Biol. 15, 1568-1574

88. Callaway, R.M., Thelen, G.C., Barth, S., Ramsey, P.W. and Gannon, J.E. (2004) Soil fungi alter interactions between the invader Centaurea maculosa and North American natives. Ecology 85, 1062-1071

89. Thorpe, A.S., Archer, V. and Deluca, T.H. (2006) The invasive forb, Centaurea maculosa, increases phosphorus availability in Montana grasslands. Appl. Soil Ecol. 32, 118-122

90. Thorpe, A. and Callaway, R.M. (2011) Biogegraphic differences in the effects of Centaurea stoebe on the soil nitrogen cycle: novel weapons and soil microbes. Biol. Invas. 13, 1435-1445

91. Baldwin, I.T. (2003) Finally, proof of weapons of mass destruction. Sci. STKE pe42 


\section{Glossary}

Allelopathy: Suppression of the growth and/or establishment of neighboring plants by chemicals released from a plant or plant parts.

Allelochemicals: Secondary compounds of plant origin that interact with their environment and possess allelopathic activities.

Homeostatis: The tendency of a biological system (organism, population, community or ecosystem) to resist changes and to remain in the state of equilibrium or change its properties in such a way as to minimize the impact of outside factors [81].

Novel weapons hypothesis (NWH): The idea that some invasive plant species produce secondary metabolites that are novel in their non-native ranges and that this novelty provides advantages to the invasive species as it interacts with native plants, microbes or generalist herbivores. 
581 Figure 1. The impact of ecosystem factors, biogeographic variations and coevolutionary

582 relationships on the production, release and activity of allelochemicals along spatial and temporal

583 scales.

584

585

High

Large scale (kilometers and beyond; years and beyond)
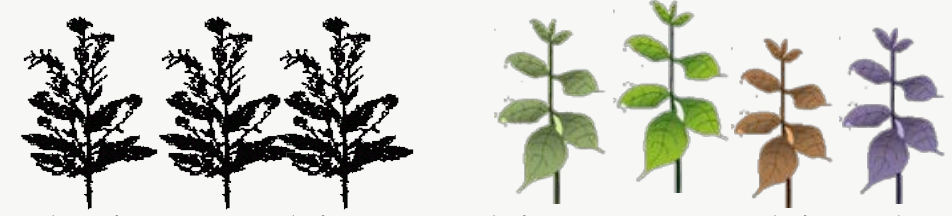

Evolutionary history, biogeographic phenomena

Medium scale (meters to kilometres; months to years)
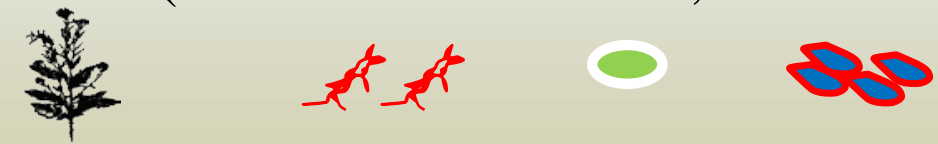

. Plant community interactions, biologival invasions, changes in soil factors

Small scale (millimeters to meters; hours to months)

Soil community interactions, chemical responses to herbivores and paftigens

Very small scale (microns to millimeters; seconds to hours)

Processes in the rhizosphere
SBat
Chemical transformation by microbes and chemical reactions

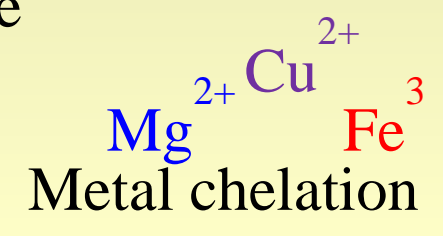

586 Low

587 Figure 1

588 
Box 1. Catechin as a novel weapon. (-)-Catechin, reported to be exuded from the roots of a Eurasian invader in North America, Centaurea maculosa (C. stoebe), was the first isolated chemical discussed as a possible 'novel weapon' [67]. Initial work on this compound used (-)- catechin but subsequent experimental studies used ( \pm )catechin because root exudates of $C$. stoebe contain a racemic mixture of $(+)$ - and ()- catechin. Early reports of consistently high rates of exudation have not been reproducible using protocols similar to those in the original experiment [see retraction, 82]. Catechin has been reported at very low concentrations in soil in the rhizospheres of $C$. stoebe [35] but high concentrations may occur periodically $[83,84]$. The phytotoxic effects of the enantiomeric form $( \pm)$-catechin, and the $(+)$ form have been demonstrated in vitro, in sand culture, in controlled experiments with field soils, and in the field [12,16,22,34 and citations within], but others have not found either the + or the - form to be phytotoxic [36,37].

Tharayil and Triebwasser [85] quantified catechin release at picomolar levels by roots of $C$. stoebe in hydroponic medium and showed a diurnal rhythm in its exudation in response to light. There is also evidence that this invader's impact is also due to interactions with the soil ecosystem including through effects on nitrogen (N) and phosphorous (P) cycling and on soil fungi [72,86-89]. Recently, Thorpe and Callaway [90] examined biogeographical differences in the responses of soil communities to C. stoebe and catechin by studying the effects of catechin on soil ammonification and nitrification in both native (Romania) and non-native (Montana) ranges. Catechin and $C$. stoebe were linked to similar reductions of resin-extractable nitrates and gross nitrification in Montana soils but not in Romanian soils where $C$. stoebe is native. As discussed below, we do not know if the consistency and rate of catechin exudation and its concentration at root-root and root-bacteria interfaces is adequate to drive substantial effects in natural systems, but biogeographical differences in ecosystem effects controlled by soil bacteria suggests that novel chemicals might affect soil nutrients by influencing soil communities as well as other plants, and that these effects have an evolutionary context.

\section{INSERT Figure I HERE}

Figure I. Abiotic and biotic ecosystem components influence the release, accumulation and activity of catechin. Unresolved issues regarding whether catechin has an important role as a novel chemical and under which environmental conditions could be addressed by studying the natural release of catechin in different ecosystems, or across gradients of invasion history. 
Factors that may influence production, release or activity of catechin

- Soil biota [32]

- Soil chemistry [12]

- Impact on nitrification [90]

- Cell wall elicitors from soil fungi [91]

- Biogeographic differences in neighbour sensitivity [63,64]

- Abiotic factors (e.g., light) [85]

\section{Key factors that we don't know}

- Phytotoxicity through natural release

- Evolutionary changes in impact over time in non-native ranges

- Potential for other chemicals in exudates or foliar leachates to alter or exceed in importance

- Differences in impact of soil biota from native and non-native ranges

- Seasonal differences in release or impact

Figure I (for Box 1) 